\title{
Reaction time and error rates in the effect of stimulus probability on character classification: Addendum
}

\author{
DEREK BESNER \\ Reading University, Reading, England \\ and \\ MAX COLTHEART \\ Birkbeck College, University of London, London, England WCIE 7HX
}

\begin{abstract}
The possibility that the additive relationship between stimulus probability and levels of processing observed by Besner (1977) could be due to an underlying speed-accuracy tradeoff was examined in the light of the error data. No evidence for such a tradeoff was found.
\end{abstract}

In a recent experiment, Besner (1977) investigated the effect of varying stimulus probability on the time taken to decide whether a probe letter shared the same name as a briefly stored target item. Contrary to the results of Pachella and Miller (1976), stimulus probability effects were evident in the latencies of "same" decisions to both same- and different-form same-name pairs (e.g., AA, Aa). These results were interpreted as indicating that Pachella and Miller's conclusion that stimulus probability has its effect during the process that derives the name of the stimulus from the visual representation is neither necessary nor sufficient. Further, the hypothesis that the visual match condition only showed effects of stimulus probability because of parallel processing, in which name matches sensitive to probability effects sometimes finished prior to visual matches which were not, was rejected on the grounds that match type and stimulus probability were additive factors. If this hypothesis were true, then an interaction in which name matches showed larger stimulus probability effects than visual matches should have been evident. This should follow if (1) visual matches do not yield stimulus probability effects; (2) the retrieval of a name is responsible for stimulus probability effects, and (3) because of independent visual and nominal comparison processes with overlapping distributions, responses to trials on which visually identical stimuli (AA) were present would sometimes be based on a nominal analysis that finished prior to a visual comparison process.
The purpose of the present note is to report the results of an omitted analysis on the error data, and thus to dismiss the possibility that stimulus probability and match type are not additive factors by virtue of a tradeoff between speed and accuracy. The importance of such analyses have been discussed at some length by Pachella (1974). In terms of the present experiment, arguments based on a demonstration of additivity between factors in the reaction time data are simply untenable if an interaction exists in the error data.

An analysis of the false "differ" error data yields no basis for supposing that such a trade exists. There was no main effect of stimulus probability $[\mathrm{F}(1,29)=.50$, $\mathrm{p}>.24]$, a significant main effect of match type $[F(1,29)=6.74, p<.025]$, and no evidence of any interaction between these factors $[\mathrm{F}(1,149)=.32$, $\mathrm{p}>.25]$.

\section{REFERENCES}

BESNER, D. Character classification: Levels of processing and the effects of stimulus probability. Bulletin of the Psychonomic Society, 1977, 9, 337-339.

Pachella, R. G. The interpretation of reaction time in information processing research. In B. Kantowitz (Ed.), Tutorials in performance and cognition. Hillsdale, N.J: Lawrence Erlbaum, 1974.

Pachella, R. G., \& Miller, J. O. Stimulus probability and same-different classification. Perception \& Psychophysics, 1976, 19, 29-34.

(Received for publication October 18, 1977.) 